\title{
Capital cultural e viagens internacionais da classe média brasileira ${ }^{[1]}$
}

\author{
Custódio Genésio da Costa Filho \\ Universidade Federal de Viçosa (UFV), Brasil \\ custodio@ufv.br \\ Renato Borges Fernandes \\ Centro Universitário de Patos de Minas (UNIPAM), \\ Brasil \\ renato@unipam.edu.br \\ Daniel Carvalho de Rezende \\ Universidade Federal de Lavras (UFLA), Brasil \\ danielderezende@dae.ufla.br
}

The cultural capital and international travel of brazilian middle class

El capital cultural y viajes internacionales de la clase media de brasil

DOI: https://doi.org/10.18472/cvt.19n2.2019.1378

Redalyc: http://www.redalyc.org/articulo.oa?

id $=115460585001$

Recepção: 16 Dezembro 2016

Aprovação: 17 Abril 2019

\section{Resumo:}

O entendimento do consumo de status em países em desenvolvimento carece de estudos demonstrando se há influência estrangeira e de que modo ela se processa na classe média nacional diante das diferenças de capital cultural. Assim, este trabalho teve como objetivo analisar o comportamento de consumo de status de diferentes níveis de capital cultural da classe média (classe B) brasileira em um contexto de viagens internacionais. Esta pesquisa qualitativa e descritiva foi realizada via grupos de foco e entrevistas individuais semiestruturadas com integrantes da classe média e, para a análise dos dados, utilizou-se a técnica de análise de conteúdo. Após a análise de diversos itens de consumo de status, esta pesquisa concluiu que as diferenças entre os diferentes níveis de capital cultural se processam nitidamente em viagens internacionais, desde o interesse e planejamento da viagem até a interação com os nativos, passando pela distinção na escolha dos destinos e na programação das viagens. Simplificadamente, o domínio de outro idioma inicia-se, e a adesão aos pacotes turísticos levam a diferenças de comportamento de consumo em viagens internacionais.

Palavras-Chave: Capital cultural, Consumo de status, Viagens internacionais.

\section{Abstract:}

The understanding of the status consumption in developed countries lacks studies demonstrating if is such foreign influence, and in which manner it is processed in national middle class when considering the differences in cultural capital. Thus, this work had the objective of analyzing the influence of "imported" products and lifestyles over the status consumption behavior of different levels of cultural capital of Brazilian middle class (class B) in a context of international travel. This qualitative and descriptive research was conducted using focus groups and individual semi-structured interviews with members of the middle class. For data analysis, the content analysis technique was used. After analyzing many status consumption items, this research concludes that the differences between the different levels of cultural capital are clearly processed in international travels, from the interest and planning of the travel to the interaction with the natives, distinguishing in the choice of destination and in the programming of the travels. In summary, the domain over another language and the adhesion to tour packages lead to differences in consumption behavior in international travels.

KEYWORDS: Cultural capital, Status consumption, International travel.

\section{Resumen:}

La comprensión de la situación del consumo en los países en desarrollo carece de estudios que muestren si hay influencia extranjera y en la forma que ella se procesa en la clase media nacional ante las diferencias culturales de capital. Este trabajo tuvo como objetivo analizar el comportamiento de consumo de status de los diferentes niveles de capital cultural de la clase media (clase B) de Brasil en un contexto de viajes internacionales. Este estudio cualitativo y descriptivo se llevó a cabo a través de grupos focales y entrevistas individuales semiestructuradas con los miembros de la clase media y para el análisis de los datos, se utilizó la técnica de análisis de contenido. Tras el análisis de diversos artículos de consumo de status, este estudio encontró que las diferencias entre 
los diferentes niveles de capital cultural se llevan claramente en los viajes internacionales ya que de la planificación de interés y viaje, para interactuar con los nativos, a través de hasta la distinción en la elección de destinos y del calendario de viajes. En pocas palabras, el dominio de idiomas empieza y la adhesión a los paquetes turísticos conducen a diferencias de comportamiento del consumidor en los viajes internacionales.

Palabras Clave: Capital cultural, Consumo de status, Viajes internacionales.

\section{INTRODUÇÃO}

Os consumidores buscam em suas práticas de consumo atender às necessidades simbólicas que estão de acordo com os códigos culturais instituídos. Além disso, o ato de consumir pode ser compreendido como um código de classificação do indivíduo na sociedade, ou seja, a forma como esse sujeito se posiciona no mundo que o cerca (BARBOSA; CAMPBELL, 2006). Esses significados são uma forma de comunicação social, já que os bens mantêm relação com outros bens, formando uma rede de significação que formam o mundo culturalmente constituído (McCRACKEN, 1986). Assim, os indivíduos podem ler e interpretar esses significados e decodificar as mensagens produzidas pelo consumo cultural.

Segundo Ponte e Mattoso (2014, p. 30), "vivemos em um mundo em que o indivíduo está imerso no universo do consumo e sendo bombardeado constantemente por estímulos como a propaganda e a moda" e, para Holt (1998), as sociedades segregam não apenas na posição econômica, mas também em critérios como a moral, a cultura e o estilo de vida, os quais são sustentados quando as pessoas interagem com seus pares sociais. Portanto, historicamente, o consumo serviu para a reprodução das fronteiras de classes sociais de inúmeras formas. Para Trigg (2001), os estilos de vida passam a ser mais relevantes do que as classes sociais como distinção social. Assim, diferenças de status oriundas do consumo têm sido observadas por estudiosos de marketing desde a obra de Veblen (1988) sobre o conceito de consumo conspícuo.

No entanto, Bourdieu (2011) demonstrou que essa distinção no consumo é mais profunda e arraigada do que se pensava, revolucionando a visão da busca de status nos processos de consumo. E a compreensão dessa dinâmica, nos países em desenvolvimento, é um campo de estudos de extrema importância, especialmente com a ascensão social de milhões de indivíduos da classe média em países como Brasil, China e Índia.

O consumo de viagens internacionais parece constituir um importante locus de consumo de status, principalmente considerando-se os argumentos de Rocha (2014), ao relatar que houve considerável aumento do consumo brasileiro de viagens impulsionado pela classe média, e de Holt (1998), para o qual, embora o consumo de turismo tenha se tornado mais popular, ainda persiste a distinção de classe, pois ela está presente na escolha da atividade turística e na forma de usufruí-la, ou seja, todos viajam, mas de formas diferentes. E as viagens compóem o universo dos produtos culturais, os quais, para Ponte e Mattoso (2014, p. 13), possuem um valor simbólico mais significativo se comparados com outros produtos, principalmente os funcionais, "isso porque o seu valor social não se esgota no ato do consumo, reproduzindo-se ao longo do tempo, de maneira que seu valor simbólico se sobrepõe aos valores de uso e de troca".

Nesse sentido, estudos específicos devem ser conduzidos em países em desenvolvimento, a fim de verificar como os processos de incorporação externa e diferenciação de classes operam em diferentes contextos, pois, ao contrário do modelo de consumo de status europeu, baseado fundamentalmente na obra de Bourdieu (1984), as classes intermediárias nos países em desenvolvimento não parecem ser tão autônomas e não definem seu gosto prioritariamente por influências internas. Estudos demonstram a enorme influência dos produtos e do estilo de vida de norte-americanos e de europeus nas classes médias desses países (USTUNER; HOLT, 2010).

Assim, diante da importância da classe média brasileira e da relevância de consumo de status de viagens internacionais, coloca-se a seguinte questão: de que modo as diferenças de capital cultural da classe média brasileira influenciam o comportamento de consumo de viagens internacionais? Baseado nessa questão, este trabalho teve como objetivo analisar a influência do capital cultural sobre o comportamento de consumo de status no contexto de viagens internacionais da classe média brasileira. 
Este trabalho se justifica pela busca por conhecimento que possa contribuir para a academia e as empresas, ao identificar de que modo se dá a influência do capital cultural no consumo de status da classe média, bem como se essa influência se dá de maneira distintiva intraclasse, operando como mecanismo classificatório de status. Pasdiora e Brei (2014, p. 808) concluem, em recente estudo, que o consumo de status no Brasil "ainda é uma teoria em desenvolvimento, que, ainda, demanda novos esforços de pesquisa para sua consolidação".

\section{REFERENCIAL TEÓRICO}

Além de sua utilidade funcional, os bens de consumo são utilizados pelos indivíduos para expressarem algo sobre si mesmos (DOUGLAS; ISHERWOOD, 2004). A necessidade de bens, nesse sentido, é decorrente do desejo do sujeito de expressar suas singularidades individuais e coletivas. Como os bens carregam consigo significados (McCRACKEN, 1986), eles são utilizados como mediadores sociais que estabelecem a combinação do sistema simbólico, que é a cultura. Os bens dão sentido às relações, sendo um meio não verbal para os homens se criarem e recriarem. Assim, para Baudrillard (1998), o ato de consumir não está restrito a uma simples relação funcional com os produtos, mas, sim, uma forma de interação social via manipulação dos signos emanados pelos objetos com base em classificações e ordenamentos culturais de distinção social.

Com relação ao status social, segundo Eastman, Goldsmith e Flynn (1999), é a posição na sociedade atribuída a uma pessoa por outras e pode ser alcançado de três maneiras: o status herdado (relacionado aos valores da aristocracia), o status realizado (conquistado por grande saber, poder ou respeito) e o status consumido (adquirido via consumo de produtos símbolos de status). Esses autores desenvolveram uma importante tipologia para avaliar o consumo de status. Eles utilizaram itens de três escalas: status (para medir o quão interessadas as pessoas estão por status na escolha de produtos), sociabilidade (para avaliar o quanto as pessoas se importam com a sua imagem perante as outras pessoas) e não funcionalidade (para medir se as pessoas abrem mão das funcionalidades dos produtos em prol do status).

No que se refere à relação entre consumo e status, foco principal deste estudo, duas grandes correntes teóricas podem ser identificadas. Uma corrente de estudos teóricos defende a teoria de Veblen e Simmel, além de estendê-la para o campo internacional. Veblen (1988) desenvolveu o conceito de consumo conspícuo, o qual vai além da função de satisfazer necessidades básicas e passa a indicar o nível de riqueza e o status social da pessoa, uma vez que, segundo Trigg (2001), as classes nobres passam a mostrar a riqueza pelas extensas atividades de lazer e de gastos excessivos com consumo e serviços. Por sua vez, Simmel (1904) desenvolveu o conceito da emulação interclasse, pela qual os indivíduos procuram ascender socialmente pela imitação dos padrões de consumo da classe superior. Considerando esses dois conceitos, surgiu o trickle-down consumption, em que as classes baixas imitam o estilo de vida e de consumo das classes mais elevadas, seria o efeito cascata do consumo conspícuo das classes altas em direção às classes abaixo.

A segunda corrente teórica advém dos estudos do sociólogo francês Pierre Bourdieu, que se centrou no consumo de status, por meio de um modelo multidimensional evidenciado na França nos anos 1960. Para ele, há um consumo cultural nacional diferenciado interclasses, o qual se opõe ao modelo de status internacional de origem vebleriana, decorrente da dominação de algumas culturas sobre outras. Bourdieu se baseia em três construtos básicos: capital cultural, habitus e campo social. Esses três elementos se relacionam e constituem o âmago da teoria de consumo de status por ele desenvolvida.

Para Bourdieu (2011), a vida social pode ser concebida como um jogo de status multidimensional em que as pessoas utilizam três diferentes tipos de recursos ("capital simbólico") em busca de distinção social: o capital econômico, que representa os recursos financeiros; o capital social, que são as relações, as afiliações organizacionais e as redes de contatos e o capital cultural, representando o conjunto de gostos socialmente raros e distintivos, habilidades, conhecimentos e práticas.

O capital cultural, interesse maior deste estudo, é o estoque acumulado de conhecimento sobre os produtos de tradições artísticas e intelectuais, que é aprendido por meio de treinamento educacional e, também, de 
censura social. O gosto estético confere distinção e exclui socialmente mais do que a simples posse ou o consumo de produtos sem a sua devida apreciação. Portanto, o consumo conspícuo de um luxo mal dominado não é nada se comparado com o gosto refinado. Significa que, outrora, a riqueza permitia o consumo que, por sua vez, conferia status. Mas, agora, o capital cultural também indica o gosto e as preferências, os quais se traduzem em status (BERGER; WARD, 2010).

No entendimento de Holt (1998), o capital cultural pode ser conferido em suas formas primárias de maneira encarnada, como implícitos conhecimentos práticos, habilidades e disposições; de maneira materializada, em bens culturais; e de maneira institucionalizada, em graus e diplomas oficiais. Nesse sentido, Bennett et al. (2009) propõem uma desagregação do conceito de capital cultural, constituído por um conjunto de ativos culturais de diferentes formas, que revelam as maneiras variadas pelas quais os recursos culturais são organizados e mobilizados por meio de diferentes tipos de relação social.

Outro importante conceito de Bourdieu é o habitus, o qual diz respeito à sutileza na percepção, na apreciação e nas práticas que dirigem o comportamento de consumo das pessoas, absorvidas, naturalmente e sem qualquer esforço, desde a infância em duas instituições básicas: a família e a escola. Nas relações históricas e nas experiências sociais ocorridas nesses dois ambientes, as pessoas vão internalizando gostos refinados que constroem a diferenciação de classe. No seio familiar, ocorre o aprendizado inicial e natural, o qual é legitimado no ambiente e no diploma escolar. Como o habitus é único, os esquemas de apreciação e de gosto são diferentes entre as classes, fazendo com que cada uma perceba de forma diferente um mesmo objeto. $\mathrm{O}$ consumo de status é, então, um forte demarcador de classe social. Observa-se, portanto, que

na relação entre as duas capacidades que definem o habitus, ou seja, capacidade de produzir práticas e obras classificáveis, além da capacidade de diferenciar e de apreciar essas práticas e esses produtos (gosto), é que se constitui o mundo social representado, ou seja, o espaço dos estilos de vida (BOURDIEU, 2011, p. 163).

Desse modo, por um lado, o habitus organiza e classifica objetos de consumo em desejo de objetos consagrados. Por outro lado, aqueles objetos que não são valorizados no campo são classificados como "desgosto" (HOLT, 1998). O habitus faz com que o conjunto de práticas de um agente seja, sistematicamente, semelhante ou distinto das práticas constitutivas de outro estilo de vida. Assim, o habitus é, ao mesmo tempo, um princípio gerador de práticas objetivamente classificáveis e um sistema de classificação de tais práticas (BOURDIEU, 2011).

Para Bourdieu (2011), o capital cultural só existe em particulares domínios institucionais, chamados de campo social. E o campo social consiste no espaço em que ocorrem as relações entre os indivíduos, grupos e estruturas sociais, com uma dinâmica que obedece a leis próprias, mobilizadas por disputas que ocorrem em seu interior com o objetivo de serem bem-sucedidos nas relações estabelecidas entre os seus componentes. Holt (1998) explica que o campo consiste em estruturas semelhantes, distintivas e autônomas (tais como: a política, as artes, a religião, a educação e os negócios). São as principais arenas em que os atores competem na hierarquia social, conforme aquisição de capital cultural do campo.

Nesse sentido, segundo Rocha (2014, p. 64), "a cultura intermedia as relações no turismo. Está presente nas escolhas do consumidor, atraindo-o ou repelindo-o, nos aspectos com os quais este consumidor se identifica e também naqueles que o diferenciam dos demais". Portanto, esse campo social do consumo, muito ligado ao hedonismo, foi explorado nesta pesquisa em busca de diferenças no comportamento de consumo de pessoas de alto e de baixo capital cultural.

Para a Organização Mundial de Turismo (OMT, 2014a, p. 1), o turismo internacional vem tendo um crescimento contínuo na economia mundial e o seu volume de negócios se equipara ao de exportações de petróleo, alimentos e automóveis. Para se ter uma ideia, em 2013, o turismo representou 9\% do Produto Interno Bruto (PIB) mundial e envolveu um em cada onze postos de trabalho (diretos, indiretos e induzidos); e, "entre 2005 e 2013, as viagens internacionais cresceram, em média, 3,8\% ao ano, alcançando o total recorde 
de 1.087 milhões de chegadas de turistas em 2013”. Embora venha registrando queda em sua participação, a Europa foi a região mais visitada, com $52 \%$ dos destinos turísticos.

Ainda segundo a OMT (2014b), em função do aumento dos níveis de renda, muitos países emergentes estão experimentando um elevado crescimento turístico nos últimos anos, entre eles alguns países da América Latina. O Brasil tem considerável participação no turismo internacional, tendo entrado no ranking dos dez maiores emissores de turistas mundiais. Para alguns destinos, a sua importância é ainda maior, por exemplo, segundo Guerreiro (2015), o Brasil é o terceiro no ranking turístico em Lisboa.

Porém, com a variação cambial e a instabilidade econômica nacional, a partir de 2014, segundo dados do Ministério do Turismo (BRASIL, 2015), a intenção de viajar para o exterior vem caindo, bem como a intenção de viajar dentro do próprio país. Por exemplo, em janeiro de 2014, 27,4\% dos entrevistados pretendiam viajar para o exterior e, em novembro de 2015, apenas 13,8\% tinham esse mesmo interesse. Mas, apesar dessa redução, em termos gerais, a classe média ainda nutre considerável intenção de realizar viagens internacionais.

\section{METODOLOGIA}

O tipo de pesquisa deste estudo quanto à abordagem foi qualitativo e, quanto à sua finalidade, optou-se pelo estudo descritivo, o qual permite "descrever 'com exatidão' os fatos e fenômenos de uma determinada realidade” (TRIVIÑOS,1987, p. 110).

A unidade de análise foi a classe média da região metropolitana de Belo Horizonte, $\mathrm{MG}$, tendo em vista sua importância econômica e cultural no contexto brasileiro. Os sujeitos da pesquisa foram homens da classe B (classe média), com idades entre 25 e 45 anos, já em uma fase adulta. Essa escolha procurou atenuar a influência de outras variáveis importantes, como sexo e idade, já que o foco é analisar o consumo cultural ligado à estrutura de classe, nos moldes de Ustuner e Holt (2010).

Como critério de seleção dos entrevistados, optou-se pela adoção do Critério de Classificação Econômica Brasil (CCEB), desenvolvido pela Associação Brasileira de Empresas de Pesquisa (Abep), também, chamado de "Critério Brasil" (Associação Brasileira de Empresas de Pesquisa - ABEP, 2014). O CCEB adotou as classes A, B1, B2, C1, C2 e D-E e neste estudo foram consideradas as pessoas classificadas na Classe B (B1 e B2), por entender que a Classe A seria a Classe Alta e as demais (C1, C2 e D-E) seriam Classes Baixas, conforme orientação de Quadros, Gimenez e Antunes (2012). Para ser considerado da Classe B, o entrevistado precisou alcançar pontuação entre 29 e 44 pontos (em uma escala que variava de 0 a 100 pontos), quando perguntado sobre os itens e características domiciliares (número de banheiros, automóveis, geladeiras, etc.), a escolaridade da pessoa de referência da família e os serviços públicos recebidos (água encanada e rua pavimentada).

Com base nos pressupostos de Bourdieu (1984), e objetivando classificar os informantes, de acordo com a intensidade de capital cultural para permitir a comparação e o entendimento da influência dos diferentes níveis no comportamento de consumo cultural, foi utilizada a escala de capital cultural, desenvolvida por Holt (1998), também utilizada por Ustuner e Holt (2010). Essa escala utiliza as seguintes medidas: nível educacional e ocupação profissional do pai, e nível educacional e ocupação do entrevistado.

Reconhecendo a importância cada vez maior das mulheres na sociedade brasileira e o grande aumento no nível de escolaridade feminino, nos últimos anos (FRIEDLAND et al., 2007) e, seguindo a metodologia adotada por Macedo (2014), foram incorporadas a escolaridade e a ocupação da mãe na metodologia aqui utilizada. No entanto, salienta-se que o status conferido a um diploma de uma universidade federal ou particular renomada seja mais qualificado e, portanto, na quantificação do capital cultural esse fator foi considerado. Cabe destacar que Bourdieu, também, fez essa distinção no caso da França, considerando mais valiosos, em termos de capital cultural, os diplomas das chamadas grandes écoles. 
Desse modo, o nível de escolaridade recebeu as seguintes pontuações: menor que o ensino médio (1 pt.); ensino médio e curso técnico completos ( 2 pts.); superior incompleto (3 pts.); curso superior completo em IES Privada não renomada (4 pts.); curso superior completo em IES Federal e Privada renomada, exemplo: PUC e FGV (5 pts.) e pós-graduação ou mestrado completos (6 pts.). Por sua vez, a ocupação profissional recebeu a seguinte pontuação: serviço manual ou doméstico que não requer qualificação ( 1 pt.); serviço de apoio ou administrativo básico que requer algum curso ou treinamento ( 2 pts.); vendas, técnico básico, gerencial básico ou pequeno empreendedor que requer formação técnica ou superior (3 pts.); alto nível técnico ou gerencial, cultural de nível básico que requer formação superior (4 pts.) e produtores culturais, profissional liberal especializado, por exemplo: médicos, advogados e engenheiros, trabalhando na área ( 5 pts.). O capital cultural é calculado via soma da pontuação total dos pais do entrevistado, dividido por dois, mais a pontuação total do próprio entrevistado. Assim, a pontuação total poderá variar de 4 a 22 pontos.

Para a coleta de dados (que ocorreu no período de julho a setembro de 2015) e objetivando avaliar as diferenças no comportamento de consumo de status entre diferentes níveis de capital cultural, foram realizados dois grupos de discussão com respondentes da classe média: um grupo com oito participantes do nível Baixo Capital Cultural (BCC), com até 13 pontos, e outro grupo, também com oito integrantes, do nível Alto Capital Cultural (ACC), acima de 13 pontos. Foram realizadas 18 entrevistas individuais semiestruturadas, sendo nove com pessoas de ACC e, também, nove com pessoas de BCC, com utilização do critério qualitativo de fechamento amostral por saturação teórica, conforme orientação de Fontanella et al. (2011). A caracterização dos entrevistados está no Quadro 1, os quais foram identificados com abreviaturas de Entrevistado "x" (E1, E2 ...).

Foi utilizada a análise de conteúdo, por meio da técnica categorial temática, para interpretação dos dados da pesquisa de campo, a qual, para Bardin (2004), compõe-se de três etapas: a) pré-análise: fase da organização, que pode utilizar vários procedimentos, tais como: leitura flutuante, hipóteses, objetivos e elaboração de indicadores que fundamentem a interpretação; b) exploração do material: aqui os dados são codificados com as unidades de registro e c) tratamento e interpretação dos resultados: categorização, que consiste na classificação dos elementos, segundo suas semelhanças e por diferenciação, com posterior reagrupamento em função de características comuns. 
QUADRO 1

Caracterização dos entrevistados

\begin{tabular}{|c|c|c|c|c|}
\hline Código & Graduação & Atividade Profissional & $\begin{array}{l}\text { Classe } \\
\text { Econômica }\end{array}$ & $\begin{array}{l}\text { Capital } \\
\text { Cultural }\end{array}$ \\
\hline \multicolumn{5}{|c|}{ Participantes do Grupo Focal de ACC } \\
\hline E1 & Psicologia & Psicólogo & $B$ & $\mathrm{ACC}$ \\
\hline E2 & Engenharia Mecatrônica & Engenheiro de Manutenção & $B$ & $\mathrm{ACC}$ \\
\hline E3 & Engenharia Civil & Engenheiro Civil & $B$ & $\mathrm{ACC}$ \\
\hline $\mathrm{E} 4$ & Engenharia Mecânica & Gerente de Operações & $B$ & $\mathrm{ACC}$ \\
\hline E5 & Ciências Econômicas & Gerente de Planejamento & $B$ & $\mathrm{ACC}$ \\
\hline E6 & Comércio Exterior & Professor Universitário & $B$ & $\mathrm{ACC}$ \\
\hline E7 & Ciência da Computação & Analista de Sistemas & $B$ & $\mathrm{ACC}$ \\
\hline E8 & Administração & Gerente Comercial & $B$ & $\mathrm{ACC}$ \\
\hline \multicolumn{5}{|c|}{ Participantes do Grupo Focal de BCC } \\
\hline E9 & Não possui & Pequeno Empresário & $B$ & $\mathrm{BCC}$ \\
\hline E10 & Não possui & Comerciante & $B$ & $\mathrm{BCC}$ \\
\hline E11 & Não possui & Supervisor Administrativo & $B$ & $\mathrm{BCC}$ \\
\hline E12 & Não possui & Representante Comercial & B & $\mathrm{BCC}$ \\
\hline E13 & Educação Física & Professor de Ensino Básico & $B$ & $\mathrm{BCC}$ \\
\hline E14 & Nã̃o possui & Gerente de Loja & B & $\mathrm{BCC}$ \\
\hline E15 & Não possui & Técnico em Informática & $B$ & $\mathrm{BCC}$ \\
\hline E16 & Não possui & Recepcionista de Hotel & B & $\mathrm{BCC}$ \\
\hline \multicolumn{5}{|c|}{ Participantes das Entrevistas Individuais } \\
\hline E17 & Geografia & Professor de Nivel Médio & $B$ & $\mathrm{ACC}$ \\
\hline E18 & Ciências Sociais & Profissional Liberal & $\mathrm{B}$ & $\mathrm{ACC}$ \\
\hline E19 & Arquitetura & Arquiteto & $B$ & $\mathrm{ACC}$ \\
\hline $\mathrm{E} 20$ & Química & Professor Universitário & $B$ & $\mathrm{ACC}$ \\
\hline E21 & Música & Músico & $B$ & $\mathrm{ACC}$ \\
\hline $\mathrm{E} 22$ & Administração & Servidor Público & $B$ & $\mathrm{ACC}$ \\
\hline E23 & Contabilidade & Professor Universitário & $B$ & $\mathrm{ACC}$ \\
\hline E24 & Comércio Exterior & Gerente Administrativo & $B$ & $\mathrm{ACC}$ \\
\hline E25 & Odontologia & Dentista & B & $\mathrm{ACC}$ \\
\hline E26 & Não possui & Supervisor de Produção & $B$ & $\mathrm{BCC}$ \\
\hline E27 & Não possui & Gerente de contas & B & $\mathrm{BCC}$ \\
\hline $\mathrm{E} 28$ & Nẫo possui & Pequeno Empresário & $B$ & $\mathrm{BCC}$ \\
\hline E29 & Não possui & Comerciante & $B$ & $\mathrm{BCC}$ \\
\hline E30 & Não possui & Pequeno Empresário & $B$ & $\mathrm{BCC}$ \\
\hline E31 & Não possui & Médio Empresário & $B$ & $\mathrm{BCC}$ \\
\hline E32 & Não possui & Mecânico & $B$ & $\mathrm{BCC}$ \\
\hline E33 & Não possui & Gerente Setorial & B & $\mathrm{BCC}$ \\
\hline E34 & Não possui & Pequeno Empresário & $B$ & $\mathrm{BCC}$ \\
\hline
\end{tabular}

Fonte: Elaborado pelos autores

\section{ANÁLISE E DISCUSSÃO DOS RESULTADOS}

\section{INTERESSE E PLANEJAMENTO DAS VIAGENS}

As diferenças entre pessoas de ACC e BCC se processam antes mesmo da viagem ocorrer, ou não ocorrer. Muitos dos entrevistados de BCC disseram não ter interesse por viagens internacionais e a justificativa, quase sempre, é o interesse prioritário por conhecer o Brasil. É o que o E33 explica ao ser questionado sobre viagens internacionais: "nunca fiz e nem tenho vontade. Acho que o Brasil tem muita coisa boa pra ser explorada antes de ir lá pra fora". Mesmo sendo inegável a riqueza turística brasileira e mesmo diante do argumento de Moretti, Zucco e Silva (2013) de que raramente a decisão por uma viagem é o resultado de um único motivo, essa justificativa parece encobrir uma grande limitação de capital cultural de um BCC: o domínio de línguas estrangeiras. 
Assim, dominar uma língua estrangeira seria muito útil em viagens internacionais, principalmente o inglês, conforme justifica o E20: "acho que a coisa que mais afeta nesse caso é o fator língua, né? Eu conheço muita gente que tem vontade, mas tem o bloqueio da língua. E até pessoas com formação... condição financeira, mas que não vão por causa da língua”. Esse aspecto é corroborado por Ustuner e Holt (2010), para os quais o habitus de pessoas de ACC turcas valoriza e ensina desde criança o inglês, o francês e o alemão, o que favorece o estilo cosmopolita dessas pessoas na idade adulta e confere status e um forte distintivo de classe.

Outra limitação está no âmbito do planejamento da viagem. Por dominar uma língua estrangeira, um ACC consegue informações de qualidade que não se consegue na língua portuguesa, ou seja, as melhores informações estão na língua local e, no máximo, em inglês. Portanto, para o E23, "pra pessoa sair de um roteiro tradicional, ela teria que pesquisar anteriormente pela internet, inclusive, na língua inglesa. Quem não domina a língua, procura informação em agências, já um que domina pode comprar um livro sobre a cidade [...]". É o que assegura Silva (2014, p. 4), para o qual "o turista recorre agora e cada vez mais a websites para pesquisar informações sobre o destino turístico que vai visitar, tendo as agências de viagens e os guias turísticos um papel cada vez menos insubstituível e relevante no fornecimento de informação turística”.

Mas isso ocorre com quem domina outros idiomas, ou seja, mesmo diante dessa tendência, ao não dominar outro idioma, um BCC fica restrito e dependente de uma agência de turismo para programar e viabilizar a sua viagem. Vale ressaltar que os agentes turísticos ainda são muito requisitados pelo público em geral, conforme identificado pelo estudo de Moretti, Zucco e Silva (2013). Possivelmente em função do contingente populacional de alto capital cultural ser relativamente bem menor do que aquele de baixo capital cultural, mas essa questão carece de maior aprofundamento e quantificação.

Diferentemente, além de conseguir informações selecionadas via livros e internet, uma pessoa de ACC consegue, também, interagir mais com outras pessoas de ACC e, principalmente, com estrangeiros, o que lhe facilita o planejamento da viagem, dispensando as agências de turismo. Com isso, os roteiros de um ACC são mais diversificados e exclusivos, o que lhes confere distinção. Portanto, um ACC ainda tem a segurança de viajar, sabendo que conseguirá levantar mais informações preciosas lá no seu destino.

Vale destacar que, neste estudo, será considerado "pacote" (package) todas aquelas situações em que o turista precisou recorrer a um agente turístico para viajar, sendo um serviço customizado (por exemplo, o forfait) ou não (entre eles oforeign independent tour) (DOMINGUES, 1997; TOMELIN, 2001), bem como o "não pacote", aqueles casos em que o turista planejou e viabilizou de maneira autônoma e independente a sua viagem turística, sem o auxílio de profissionais e agentes turísticos.

\section{DESTINOS TRADICIONAIS VERSUS DIFERENCIADOS}

Após o planejamento, o tipo de programação: “pacote” versus "não pacote”, parece fazer toda a diferença ao longo da viagem, pois uma pessoa de BCC, diante das dificuldades para programar a sua viagem, acaba optando pela orientação de agentes turísticos, segundo o E24, ela se "sente mais segura em um pacote". Mas os pacotes turísticos normalmente direcionam o roteiro de viagem para destinos tradicionais. Para esse mesmo entrevistado, pessoas de BCC, que nunca viajaram, normalmente "têm muito interesse de ir para os EUA", e os entrevistados E19 e E20, respectivamente, acrescentam: "eles pensam em Paris, Nova Iorque. Gostam de Cruzeiros [marítimos]" e "eles vão todo ano pra Miami, pra Disney".

Segundo o E31, em uma viagem com um grupo de familiares de profissionais da sua área, eles foram para Lisboa, Madri e Paris. E, mesmo não dominando o inglês (o que ele agora passou a se interessar e a estudar), ele se aventurou como muitos outros e fez uma viagem inesquecível: "estou fazendo [inglês], se eu soubesse, ajudaria, mas não tive muita dificuldade, o pessoal é muito acostumado a lidar com o turista”.

O último trecho de sua fala indica que, nas cidades, tidas como tradicionais, ele foi para pontos turísticos também tradicionais, nos quais os atendentes das lojas e dos restaurantes já estão familiarizados com os mais diversos estilos de turistas. E isso parece agregar pouco à sua experimentação da cultural local. Na tipologia 
de Yiannakis e Gibson (1992), consta o tipo "turistas organizados em massa", caracterizados pelas viagens em pacotes turísticos, tiradores de fotos e compradores de souvenires; esse estilo de turista parece próximo das pessoas de BCC da classe B. Já os estilos "antropólogos" (interessados em interagir com a população, falando a língua e experimentando a comida local), "exploradores" (interessados em explorar lugares novos) e os "buscadores" (interessados em ampliar o seu conhecimento pessoal) são mais próximos das pessoas de ACC.

Embora sejam para destinos tradicionais e com pouca experimentação cultural local, pessoas de BCC se demonstram satisfeitas com as suas viagens internacionais. Elas aparentam estar felizes e realizadas ao visitarem aquelas cidades destacadas na mídia e aclamadas pela elite e pelos seus pares e, em vez de se aventurarem em destinos e lugares diferentes, elas preferem o conforto e o glamour garantido dos destinos tradicionais.

Mas buscar destinos tradicionais é uma prática criticada por pessoas de ACC, até porque, segundo elas, pessoas de BCC, em busca de status, têm mais necessidade de mostrar suas viagens em redes sociais e nos círculos de amizades; para o E24, eles "vão para os lugares turísticos de modismos, fazendo selfies em lugares comuns". E o E20 acrescenta dizendo que pessoas de BCC, nas viagens, priorizam a "quantidade", em vez da "qualidade": "vai no pacote e conhece 20 países em 10 dias... Vai passar um mês na Europa e quer conhecer o máximo de países e ter o maior número de carimbos no passaporte, em vez de alugar um carro, ir de trem e conhecer em profundidade" um número menor de destinos.

Por outro lado, em viagens do tipo "não pacote", de modo geral, as pessoas de ACC fazem sua própria programação e viajam em menor número de pessoas. Segundo o E20, eles "buscam variar os roteiros e vão para lugares exóticos: Etiópia, China, Nepal e Tailândia. Não são lugares que você vê luxo, mas, sim, uma cultura diferente". E o E24 acrescenta que pessoas de ACC valorizam lugares diferentes, novos, exclusivos, por exemplo: "todo mundo vai pra Miami, mas do lado de Miami tem um lugar maravilhoso, Key West que é uma cidade maravilhosa, rica [...]. A pessoa vai pra Orlando, mas não vai pra Key West, por exemplo". Nessa mesma linha e além de Key West nos EUA, esse entrevistado acrescenta ainda Los Roques, na Venezuela. E ele completa dizendo que essa preferência "vai variar de acordo com [...] quem é mais intelectualizado e tem mais acesso à informação do que quem tem acesso ao dinheiro sem ter referências aos locais”, ou seja, o capital cultural, traduzido em gostos e preferências refinados, pode influenciar mais na escolha do destino turístico do que o capital econômico. E esse entrevistado adiciona ainda um aspecto importante no processo de distinção: para ele, as pessoas de ACC descobrem novos destinos e usufruem desses destinos até que caiam no gosto comum; daí, vão buscar novos destinos exclusivos e exóticos, como é o caso de "San Andrés, na Colômbia, em vez de Cartagena”. Esse parece ser um esforço e um risco dos quais uma pessoa de BCC não se dispõe, uma vez que são inúmeros os destinos turísticos tradicionais a serem explorados com conforto e com "satisfação garantida".

Essas formas de distinção condizem com os resultados da pesquisa de Holt (1998), realizada nos EUA, pois, para esse autor, pessoas de BCC preferem atividades de consumo coletivas e buscam uma homogeneização de produtos. Por exemplo, em viagens, elas buscam destinos populares (Disney World, praias, entre outros) e pacotes turísticos planejados. Já as pessoas de ACC buscam um estilo único e original, por meio de objetos de consumo. Elas buscam autenticidade e individualização do seu consumo. Por exemplo, em viagens elas evitam pacotes produzidos em massa (tidos como artificiais) e procuram uma experiência "autêntica" que é encontrada pela exploração e casualidade.

Vale ressaltar que os entrevistados de ACC admitiram conhecer os ditos destinos tradicionais, mas buscam se diferenciar, contando histórias e experiências de outros destinos, os exclusivos. E, mesmo tendo viajado para os destinos tradicionais, eles ressaltam programações diferentes daquelas das pessoas de BCC, de modo a também garantirem status, ainda que viajando para os mesmos lugares. 


\section{PROGRAMAÇÃO E INTERAÇÃO}

Ainda que estejam visitando as mesmas cidades, pessoas de BCC e ACC se distinguem em função da programação: uma mais comercial e a outra mais cultural, ou seja, pessoas de BCC vão aos lugares e atrações turísticos mais sofisticados, badalados e tradicionais, que lhes permitem ser facilmente identificados nas divulgações em redes sociais, bem como priorizam sobremaneira as compras de itens que lhes conferem status (roupas, calçados, celulares, entre outros). Por outro lado, pessoas de ACC buscam experiências culturais e exóticas, em museus, teatros, restaurantes e colocam essas experiências em seus repertórios e diálogos de modo a também conseguirem status.

Nesse sentido, E17 explica que, em uma viagem à Buenos Aires, ele teve contato com pessoas de BCC e elas adquiriram uma espécie de passaporte para diversas boates da cidade, pelas quais se revezavam ao longo dos dias da semana. Assim, tais pessoas curtiam as noites nas boates e quase nada faziam ao longo do dia. Ao contrário, tal entrevistado preferiu fazer um roteiro mais cultural (museus, teatros, entre outros) que incluiu até a ida ao cemitério da Recoleta (Cementerio de la Recoleta) e ao bairro pobre de La Boca.

Já o E28 admitiu, em sua visita também a Buenos Aires, que "lá tem muitos restaurantes, e quando você vai até engorda, eles comem muita carne. Fui muito em Porto Madeiro [região de restaurantes sofisticados]”. E sua visita foi pouco produtiva, em termos de interação e atividades culturais, tanto que ele declarou que achou Buenos Aires não muito diferente de Belo Horizonte. Em outra situação, o E25 relatou que, em sua viagem a Praga (República Tcheca), ele foi a "um concerto em uma igreja renascentista e depois fui a um show do Lenny Kravitz”. Ao contar a sua programação a pessoas de BCC, eles lhe disseram que iriam somente ao show do Lenny Kravitz e não demonstraram qualquer interesse pelo concerto na igreja renascentista.

A programação mais restrita de um BCC é muito em função do script que ele recebe de guias, agentes de viagens e dos seus pares (ou companheiros de viagem), que valorizam os mesmos pontos turísticos. Segundo Silva (2014, p. 16), em função das limitações impostas, "os pacotes tradicionais feitos pelas agências permitem pouca ou nenhuma alteração por parte do seu consumidor”. A necessidade de ir aos pontos turísticos predefinidos, que são símbolos de status, é tamanha que um BCC deixa de aproveitar e conhecer outros pontos turísticos igualmente ou mais interessantes. $O$ roteiro parece funcionar como uma viseira, que o cega e o hipnotiza em direção aos locais aclamados. O E24 fornece alguns exemplos nesse sentido: um conhecido considerado por ele como BCC

só queria ir em determinados lugares, não via outros. Então, às vezes ele estava procurando, por exemplo, um prédio art déco " $\mathrm{x}$ " [estilo arquitetônico], que foi determinado dentro do guia ou que foi falado pra ele, e ele passou por vários prédios art déco e nem viu os prédios.

E esse entrevistado ainda conclui: eles "não têm um desejo próprio [...]; estão [...] atendendo mais uma vez a essa linha de comportamento que vem de outras pessoas que são da classe que ela queria pertencer, e deixando de ter essas experiências mais ricas, que são as mais simples mesmo, né?”. Visitar e necessariamente registrar os locais badalados é indispensável às pessoas de BCC. Assim, elas conseguem expor as fotos (principalmente as selfies) nas redes sociais, durante e depois das viagens.

Portanto, pessoas de BCC acabam fazendo um roteiro bem comercial, pelo fato de irem aos locais mais turísticos e pelo aspecto literalmente comercial: as compras. Obviamente, e em função dos altos preços dos produtos estrangeiros no Brasil, indistintamente, pessoas de BCC e de ACC fazem compras no exterior. Porém, as pessoas de ACC asseguram que planejam e não colocam as compras como objetivo principal da viagem. Elas pesquisam na internete em sites de lojas nos destinos e buscam fazer uma compra mais consciente e vantajosa.

Com um perfil de ostentação mais ligado aos itens materiais e de marca, pessoas de BCC aproveitam boa parte das suas viagens para fazer compras, isso quando as viagens não são exclusivamente para as compras (por exemplo, para Miami - EUA). Assim, pessoas de BCC aproveitam a viagem para comprar itens que lhes 
conferem status diante de seus pares no Brasil, principalmente aqueles de fácil visualização: roupas, calçados, celulares, relógios, entre outros. Para o E24, o frenesi pelas compras de pessoas de BCC o impressiona:

\begin{abstract}
Você vê, nos Estados Unidos, grupos de brasileiros em determinadas lojas desesperados pra comprar e querendo as mesmas coisas [...]. Os próprios vendedores, quando veem que é brasileiro, já querem aproveitar da situação, né? Porque sabem que vão comprar [...] e sem muita referência. Assim, muito influenciados por determinadas marcas. E, às vezes, o cara não tá nem preocupado onde ele vai dormir. Por exemplo, hotel pra ele é só pra dormir, então ele dorme em qualquer lugar. Mas quer comprar, quer consumir, pra poder chegar depois e contar pra galera. Eu acho que tem muito isso, desses itens que dão status aqui no Brasil, por exemplo [...] celulares, tablets [...] Compra um iphone, não sei quantos dólares. E vai comer no MC Donald's todo dia, ao invés de gastar aquele dinheiro, ali, pra ver uma peça, que vai enriquecer, ou [...] até mesmo estudar o idioma local, que seja, né? Mas, ele prefere comprar o celular [...].
\end{abstract}

Esse comportamento de compra é bastante frequente em alguns destinos, principalmente estadunidenses. É tanto que o momento atual de crise financeira brasileira, que culminou com a alta da cotação do dólar, segundo Ribeiro (2015), prejudicou o comércio em cidades como Orlando, nos EUA.

Dominar outro idioma, principalmente o inglês, faz toda a diferença em relação a fazer uma viagem sem utilizar um pacote turístico e, por sua vez, o "não pacote" é decisivo para uma maior interação com os nativos e pessoas de outras línguas e para uma experienciação mais aprofundada do universo local. Isso é reforçado por Fernandes (2014, p. 8), o qual declara que "o domínio do idioma estrangeiro é bastante importante no processo de integração".

Pessoas de ACC conseguem interagir melhor com estrangeiros de diferentes nacionalidades, em diversos ambientes, ao longo das viagens internacionais, pela internet e até mesmo no Brasil. Assim, eles trocam informações, descobrem lugares e, muitas vezes, são recebidos pelos amigos estrangeiros em diferentes viagens. Ao dominar a língua local ou o inglês e ao se desvencilharem de guias turísticos, eles conseguem interagir com as pessoas nativas e obtêm informações preciosas sobre situações e pontos turísticos exclusivos e diferenciados, muitas vezes, frequentados somente por pessoas locais, sem a movimentação turística tradicional. Portanto, eles vivenciam o cotidiano e experienciam a cultura local, sem a maquiagem comercial e turística, uma vez que, para Thompson e Arsel (2010), os turistas cosmopolitas valorizam os costumes locais e buscam experimentar a cultura do país na sua forma autêntica, via estabelecimentos (lojas, restaurantes, entre outros) e pessoas.

Nesse sentido, é comum eles alugarem carros e usarem transporte público em vez de usarem passeios fretados, em grupos ou com guias. É mais comum evitarem os hotéis tradicionais e optarem por estadias em casas de nativos, locação de casas ou apartamentos, ou até mesmo hospedagem em hostel. Essas opções são preferidas até porque suas estadias em uma mesma cidade costumam ser mais duradouras, eles não se satisfazem em passar por um ponto turístico, tirar fotos e seguir em frente para cumprir o apertado roteiro. Eles interagem mais e permanecem mais tempo em contato com a cultura e a história local.É o que explica o E23: "em Buenos Aires até alugamos um apartamento. E vivenciamos o dia a dia da cidade: ir à padaria, pegar um ônibus $[\ldots .$. ”.

\title{
CONSIDERAÇÕES FINAIS
}

Ao comparar as diferenças de consumo de status entre pessoas de BCC e pessoas de ACC da classe média em relação às viagens internacionais, foram identificados diversos aspectos distintivos entre pessoas de ACC e de BCC. As diferenças já se expressaram no interesse e no planejamento das viagens internacionais, em que muitas pessoas de BCC demonstram desinteresse por viagens internacionais em função de seu baixo capital cultural, principalmente por não dominar outros idiomas, e aquelas que fazem viagens internacionais as realizam via pacotes turísticos de agências de turismo. Já as pessoas de ACC buscam incrementar o seu repertório e status cultural nas viagens internacionais e conseguem e preferem planejá-las, sem o envolvimento de agências de turismo, com base no domínio de outras línguas, de contatos e de outras fontes de informações mais ricas (internet, livros, entre outras). 
Desse modo, as pessoas de ACC parecem preferir e buscar destinos diferenciados e exclusivos para as suas viagens internacionais, o que lhes confere considerável status em suas incursões mais aprofundadas e qualitativas. Em função dos pacotes turísticos, de modo geral, as pessoas de BCC viajam para destinos tradicionais e badalados, sendo os preferidos os EUA e a Europa. Elas também buscam status ao percorrer maior volume de destinos e ao divulgá-los socialmente. A distinção também se processa na programação: pessoas de BCC cumprem um script e frequentam lugares mais "comerciais" (conhecidos e de compras); já as pessoas de ACC preferem lugares para experimentar a cultura local e o exótico. Portanto, um ACC se esforça para descobrir novos destinos e se vangloria disso, e um BCC prefere não se arriscar e opta por lugares reconhecidos e com boa estrutura turística.

Ao dominar outro idioma e buscar lugares diferentes e pouco turísticos, pessoas de ACC priorizam e conseguem maior interação com os nativos e a cultura local, bem como com estrangeiros de outras nacionalidades; isso é possível via hospedagem e transporte alternativos. Pessoas BCC interagem superficialmente com os nativos, estão mais preocupadas em registrar os locais afamados e em realizar as suas compras de produtos consagrados e de marcas. Assim, por status, pessoas de ACC, com um perfil mais intelectual, buscam ampliar o seu repertório e a sua distinção cultural, e pessoas de BCC, mais materialistas, procuram consumir itens (produtos e lugares) que demonstrem seu capital pecuniário.

Vale destacar que este estudo carrega diversas limitações e entende que seria também importante pesquisar participantes de diferentes regiões brasileiras, classes econômicas, fases da vida, faixas etárias, gêneros, etnias, entre outros. Ademais, incluir novas categorias de avaliação do capital cultural (foram utilizadas aqui somente a escolaridade e a atividade profissional dos entrevistados e de seus pais) e considerar os conceitos de capital social na avaliação de consumo de status. Assim, ao expandir esta pesquisa com outras, também qualitativas, sugerem-se pesquisas quantitativas abrangentes, as quais contribuiriam para a consolidação dos conceitos de capital cultural e a sua influência no consumo de status.

\section{REFERÊNCIAS}

ASSOCIAÇÃO BRASILEIRA DE EMPRESAS DE PESQUISA (ABEP). Critério de classificação econômica Brasil. 2014. Disponível em: . Acesso em: 20 dez. 2014

BARBOSA, L.; CAMPBELL, C. (Org.). Cultura, consumo e identidade. Rio de Janeiro: FGV, 2006. 204 p.

BARDIN, L. Análise de conteúdo. 3. ed. Lisboa: Setenta, 2004. 223 p.

BAUDRILLARD, J. Selected writings. Palo Alto: Stanford University Press, 1998. 304 p.

BENNETT, T. et al. Class, culture, distinction. London: Routledge, 2009. $336 \mathrm{p}$

BERGER, J.; WARD, M. Subtle signals of inconspicuous consumption. Journal of Consumer Research, Gainesville, v. 37, n. 4, p. 555-569, 2010.

BOURDIEU, P. A distinção: crítica social do julgamento. Porto Alegre: Zouk, 2011.560 p . Distinction. London: Routledge, 1984.613 p.

BRASIL. Ministério do Turismo. Sondagem do consumidor: intenção de viagem. Brasília, 2015. Disponível em: http://www.dadosefatos.turismo.gov.br/export/sites/default/ dadosefatos/conjuntura_economica/ sondagem_consumidor_viagem/downloads_sondagem_consumidor/2015_11_Sondagem_Novembro.pdf. Acesso em: $21 \mathrm{dez} .2015$

DOMINGUES, C. M. Prontuário turístico. Lisboa: Instituto Nacional de Formação Turística. 1997.361 p

DOUGLAS, M.; ISHERWOOD, B. O mundo dos bens. Rio de Janeiro: UFRJ, 2004. 304 p

EASTMAN, J. K.; GOLDSMITH, R. E.; FLYNN, L. R. Status consumption in consumer behavior: scale development and validation. Journal of Marketing Theory and Practice, London, v. 7, n. 3, p. 41-52, 1999

FERNANDES, D. A. A mulher brasileira migrante nas mídias da Europa: uma revisão teórica sobre a representação de uma minoria no jornalismo. Naveg@mérica, n. 13, p. 1-26, 2014. 
FONTANELLA, B. J. B. et al. Amostragem em pesquisas qualitativas: proposta de procedimentos para constatar saturação teórica. Cadernos de Saúde Pública, Rio de Janeiro, v. 27, n. 2, p. 389-394. 2011

FRIEDLAND, L. et al. Capital, consumption, communication, and citizenship: the social positioning of taste and civic culture in the United States. The Annals of the American Academy of Political and Social Science, Lancaster, v. 611, n. 1, p. 31-50, 2007.

GUERREIRO, M. I. S. Análise exploratória dos turistas estrangeiros: o caso dos pastéis de Belém. 2015. 61 p. Dissertação (Mestrado em Economia Internacional e Estudos Europeus) - Lisboa School of Economics \& Management, Lisboa, 2015.

HOLT, D. Does cultural capital structure American consumption? Journal of Consumer Research, Gainesville, v. 25, p. 1-25, June 1998

MACEDO, S. B. As dimensões do consumo da nova classe média e a influência do capital cultural. 140 p. Dissertação (Mestrado em Administração) - Universidade Federal de Lavras, Lavras, 2014.

MCCRACKEN, G. Culture and consumption: a theoretical account of the structure and movement of the cultural meaning of consumer goods. Journal of Consumer Research, Gainesville, v. 13, n. 1, p. 71-84, 1986.

MORETTI, S. L. A.; ZUCCO, F. D.; SILVA, D. Motivação para viajar, fontes de informação e qualidade percebida do serviço: um estudo com turistas da Oktoberfest, em Munique (RFA) e Blumenau (BR). Caderno Virtual de Turismo, Rio de Janeiro, v. 13, n. 3, p. 409-424. 2013.

Organização Mundial do Turismo. Panorama do turismo no mundo 2013. 2014a. Disponível em: http://www.dadosefatos.turismo.gov.br/export/sites/default/ dadosefatos/estatisticas_indicadores/ downloads_estatisticas/Estatistica_e_indicadores_Turismo_no_mundo_2013.pdf. Acesso em: $10 \mathrm{dez} .2015$

ORGANIZACIÓN MUNDIAL DEL TURISMO. Panorama OMT del turismo internacional. 2014b. Disponível em: < http://www.dadosefatos.turismo.gov.br/export/ sites/default/dadosefatos/estatisticas_indicadores/ downloads_estatisticas/OMT_Turismo_highlights_2014_sp.pdf >. Acesso em: 20 nov. 2015.

PASDIORA, M. A.; BREI, V. A. A formação do hábito de consumo infantil: uma análise crítica da Teoria de Consumo de Status aplicada às classes sociais altas e baixas no Brasil. Organização \& Sociedade, Salvador, v. 21, n. 68, p. 789-813, 2014.

PONTE, L. F.; MATTOSO, C. Q. Capital cultural e o consumo de produtos culturais: as estratégias de consumo de status entre mulheres da nova classe média. Revista Brasileira de Marketing, São Paulo, v. 13, n. 6, p. 18-33, 2014.

QUADROS, W. J.; GIMENEZ, D. M.; ANTUNES, D. J. N. O Brasil e a nova classe média dos anos 2000. Carta Social e do Trabalho, Campinas, n. 20, p. 1-11, out./dez. 2012.

Ribeiro, V. Orlando sente o inferno brasileiro da recessão. Jornal Estado de Minas, Belo Horizonte, 2015. Disponível em: http://www.em.com.br/app/noticia/economia/internas_ economia/ orlandosenteoinfernobrasileirodarecessao.shtml. Acesso em: 15 dez. 2015.

ROCHA, A. R. C. Significados atribuídos a cruzeiros marítimos: um estudo multimétodos. 2014.310 p. Tese (Doutorado em Administração de Empresas) - Pontifícia Universidade Católica, Rio de Janeiro, 2014.

SILVA, C. P. C. L. O papel da internet na oferta de informação turística. 2014.68 p. Dissertação (Mestrado em Gestão) - Universidade Lusíada de Lisboa, Lisboa, 2014

SIMMEL, G. Fashion. International Quarterly, Oxford, v. 10, p. 275-291, 1904.

THOMPSON, C. J.; ARSEL, Z. The starbucks brandscape and the discursive mapping of local coffee shop cultures. Madison: University of Wisconsin, 2010.59 p.

TOMELIN, C. A. Mercado de agências de viagens e turismo: como competir diante das novas tecnologias. São Paulo: Aleph, 2001. 142 p.

TRIGG, B. Veblen, Bourdieu and conspicuous consumption. Journal of Economics, Cambridge, v. 35, n. 1, p. 99-115, 2001.

TRIVIÑOS, A. N. S. Introdução à pesquisa em ciências sociais: a pesquisa qualitativa em educação. São Paulo: Atlas, 1987. $175 \mathrm{p}$ 
Custódio Genésio da Costa Filho, et al. Capital cultural e viagens internacionais da classe média...

USTUNER, T.; HOLT, D. B. Toward a theory of status consumption in less industrialized countries. Journal of Consumer Research, Gainesville, v. 37, p. 37-56, June 2010.

VEBLEN, T. A teoria da classe ociosa: um estudo econômico das instituições. São Paulo: Abril, 1988. 182 p.

YIANNAKIS, A.; GIBSON, H. Roles tourists play. Annals of Tourism Research, New York, v. 19, n. 2, p. 287-303, 1992.

\section{Notas}

[1] Uma versão preliminar deste trabalho foi apresentada no XIX SemeAd 2016. 